\title{
Membrane Channel Forming Polypeptides. 270-MHz Proton Magnetic Resonance Studies of the Aggregation of the 11-21 Fragment of Suzukacillin in Organic Solvents ${ }^{\dagger}$
}

\author{
M. Iqbal and P. Balaram*
}

ABSTRACT: $270-\mathrm{MHz}{ }^{1} \mathrm{H}$ NMR studies of the 11-21 suzukacillin fragment Boc-Gln-Aib-Leu-Aib-Gly-Leu-Aib-ProVal-Aib-Aib-OMe (11-G) and its analogue Boc-Ala-AibLeu-Aib-Gly-Leu-Aib-Pro-Val-Aib-Aib-OMe (11-A) have been carried out in $\mathrm{CDCl}_{3}$ and $\left(\mathrm{CD}_{3}\right)_{2} \mathrm{SO}$. The $\mathrm{NH}$ chemical shifts and their temperature coefficients have been measured as a function of peptide concentration in both solvents. It is established that replacement of Gin by Ala is without effect on backbone conformation. Both peptides adopt highly folded $3_{10}$ helical conformations stabilized by seven intramolecular $4 \rightarrow 1$ hydrogen bonds. Nonlinear temperature dependences are demonstrated for free $\mathrm{NH}$ groups in the $\mathrm{Gln}(1)$ peptide.

\begin{abstract}
A lamethicin, suzukacillin, and related $\alpha$-aminoisobutyric acid (Aib) ${ }^{1}$ containing membrane channel forming polypeptides (Figure 1) can alter the permeability properties of artificial lipid membranes (Mueller \& Rudin, 1968; Boheim \& Kolb, 1978). In particular, alamethicin, suzukacillin, and trichotoxin A-40 (Boheim et al., 1976; Bruckner et al., 1979) form channels that exhibit voltage-dependent conductance characteristics, a feature that is reminiscent of excitable membranes (Hall, 1978). Conformational analysis of synthetic fragments of alamethicin (Nagaraj et al., 1979; Rao et al., 1979, 1980; Prasad et al., 1979; Nagaraj \& Balaram, 1981a; Smith et al., 1981) and suzukacillin (Iqbal \& Balaram, $1981 \mathrm{a}, \mathrm{b})$ has led to the suggestion that these hydrophobic polypeptides adopt largely $3_{10}$ helical conformations. Since such helical structures have very small internal diameters, passage of cations through the helix interior is ruled out. Transmembrane channels must then be composed of aggregates of these rodlike helical molecules, to yield a central aqueous core (Mathew et al., 1981; Edmonds, 1979). This proposal is in marked contrast to the suggested models for the gramicidin A channel (Urry, 1971; Veatch et al., 1974; Bradley et al., 1978; Weinstein et al., 1979), where passage of cations occurs through the hydrophilic interior of the helical structures.

An examination of the sequences in Figure 1 shows that these polypeptides are composed of predominantly hydrophobic residues, with polar groups present only at the carboxyl terminal. There is, however, a lone Gln residue approximately in the center of the apolar sequence in alamethicin [Gln(7)], suzukacillin [Gln(11)], hypelcin $A[G \ln (7)]$, and trichotoxin $A-40[G \ln (6)]$. In the shorter peptides, antiamoebins and emerimicins, the Gln residue is closer to the C-terminal. Association of such apolar peptides in the lipid phase may be facilitated by hydrogen bonding involving the carboxamide
\end{abstract}

\footnotetext{
${ }^{\dagger}$ From the Molecular Biophysics Unit, Indian Institute of Science, Bangalore 560 012, India. Received May 29, 1981. This work has been supported by a grant from the Department of Science and Technology, Government of India. M.I. is the recipient of a Teacher-Fellowship of the University Grants Commission. P.B. is the recipient of a UGC Career Award.
}

Aggregation is mediated by intermolecular hydrogen bonds formed by solvent-exposed $\mathrm{NH}$ groups. A major role for the Gln side chain in peptide association is suggested by differences in the NMR behavior of the $\mathrm{Gln}(1)$ and $\mathrm{Ala}(1)$ peptides. For the $\mathrm{Gln}(1)$ peptide in $\mathrm{CDCl}_{3}$, the carboxamide side chain carbonyl group forms an intramolecular hydrogen bond to the peptide backbone, while the trans side chain NH shows evidence for intermolecular interactions. In $\left(\mathrm{CD}_{3}\right)_{2} \mathrm{SO}$, the cis carboxamide $\mathrm{NH}$ is involved in intermolecular hydrogen bonding. The possible role of the central Gln residue in stabilizing aggregates of peptide channel formers is discussed, and a model for hexameric association is postulated.

group of Gln. A major interest of this laboratory has been to establish the structural characteristics of membrane channels formed by Aib-containing polypeptides. Previous NMR studies have suggested that the 1-10 and 11-21 suzukacillin fragments adopt highly folded $3_{10}$ helical conformations, stabilized by intramolecular $4 \rightarrow 1$ hydrogen bonds in organic solvents (Iqbal \& Balaram, 1981a,b). However, the problem of peptide aggregation in both polar and apolar media needs to be addressed. In this report, we examine by $270-\mathrm{MHz}^{1} \mathrm{H}$ NMR spectroscopy the aggregation behavior of the 11-21 suzukacillin fragment, Boc-Gln-Aib-Leu-Aib-Gly-Leu-AibPro-Val-Aib-Aib-OMe (11-G), in organic solvents like $\mathrm{CDCl}_{3}$ and $\left(\mathrm{CD}_{3}\right)_{2} \mathrm{SO}$. This fragment has been chosen as a model system, since excellent resolution of amide NH resonances is obtained. Studies on the peptide Boc-Ala-Aib-Leu-Aib-GlyLeu-Aib-Pro-Val-Aib-Aib-OMe (11-A) are also reported to enable an assessment of the role of the Gln side chain in promoting peptide association.

\section{Materials and Methods}

The peptides Boc-Ala-Aib-Leu-Aib-Gly-Leu-Aib-ProVal-Aib-Aib-OMe (11-A) and Boc-Gin-Aib-Leu-Aib-GlyLeu-Aib-Pro-Val-Aib-Aib-OMe (11-G) were synthesized by solution phase procedures as described for alamethicin (Nagaraj \& Balaram, 1981b). All peptides were homogeneous by TLC on silica gel and were characterized by $270-\mathrm{MHz}^{1} \mathrm{H}$ NMR. Detailed synthetic procedures will be described elsewhere.

${ }^{1} H$ NMR spectra were recorded on a Bruker WH-270 FT-NMR spectrometer at the Bangalore NMR Facility as described earlier (Iqbal \& Balaram, 1981a,b). Peptide concentrations in $\mathrm{CDCl}_{3}$ and $\left(\mathrm{CD}_{3}\right)_{2} \mathrm{SO}$ were varied over the range $1-50 \mathrm{mg} / \mathrm{mL}$. Concentrations were varied by dilution of a concentrated stock solution. Solvent titration experiments were carried out by adding a peptide solution in $\left(\mathrm{CD}_{3}\right)_{2} \mathrm{SO}$ in aliquots to a $\mathrm{CDCl}_{3}$ solution, maintaining a fixed concentration of $10 \mathrm{mg} / \mathrm{mL}$.

\footnotetext{
${ }^{1}$ Abbreviations used: Aib, $\alpha$-aminoisobutyric acid; Boc, tert-butyloxycarbonyl; OMe, methyl ester.
} 


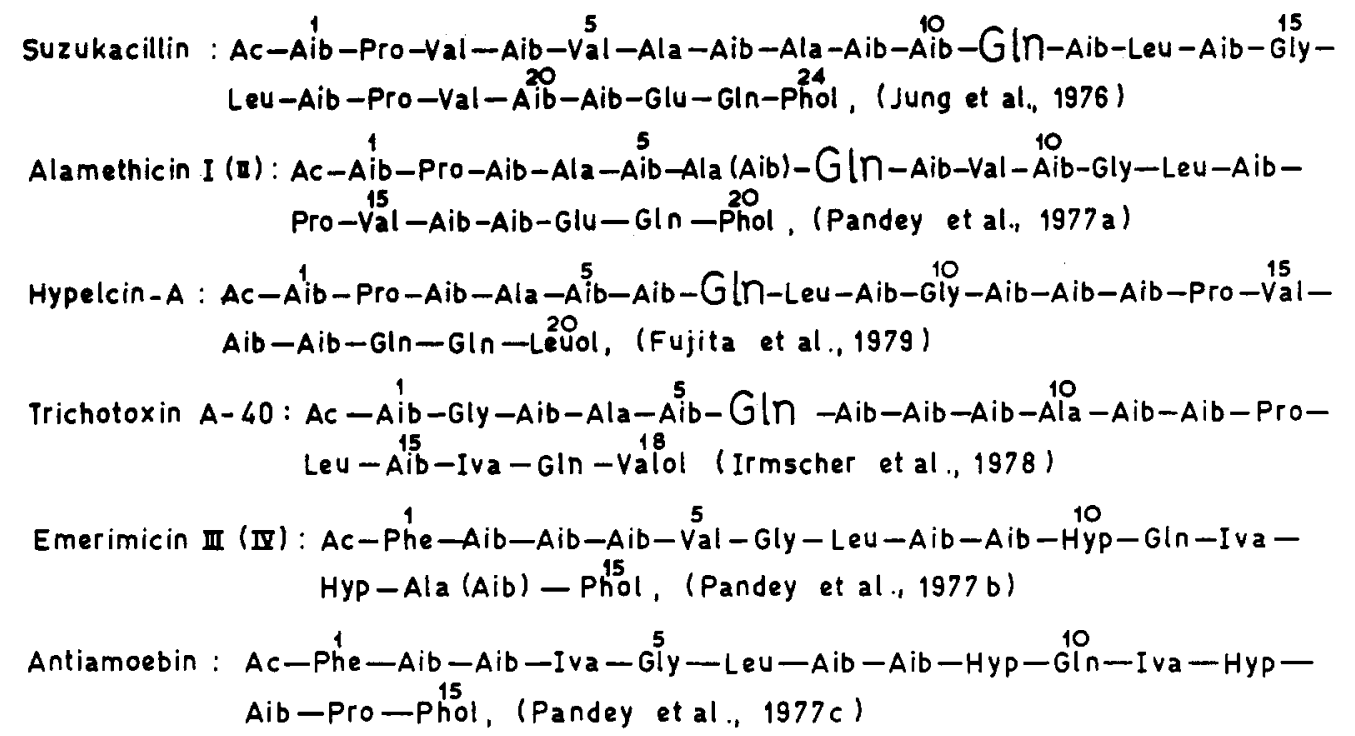

FIGURE 1: Sequence of Aib-containing membrane channel forming polypeptides.
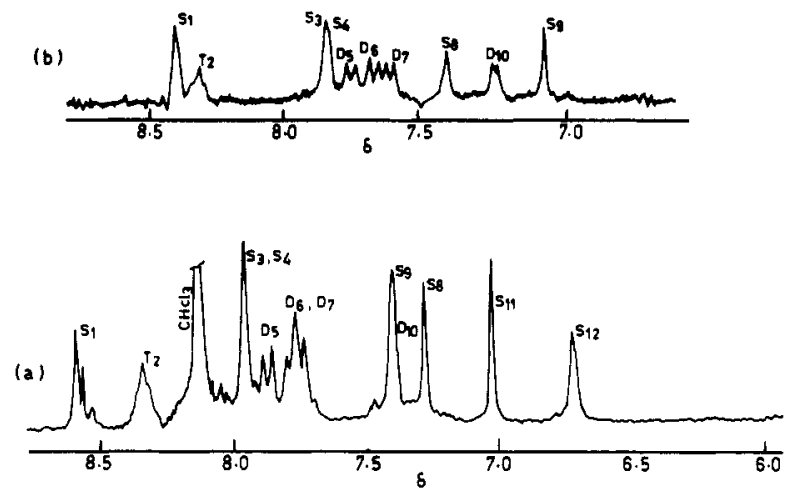

FIGURE 2: Partial 270-MHz ${ }^{1} \mathrm{H}$ NMR spectra (NH region) of peptides in $\left(\mathrm{CD}_{3}\right)_{2} \mathrm{SO}$ : (a) $11-\mathrm{G}(0.00086 \mathrm{M}, 1 \mathrm{mg} / \mathrm{mL})$. (b) $11-\mathrm{A}(0.0013$ $\mathrm{M}, 1.5 \mathrm{mg} / \mathrm{mL}$ ).

Results

Chemical Shifts of NH Resonances. Figure 2a shows the low-field region of the $270-\mathrm{MHz}{ }^{1} \mathrm{H}$ NMR spectrum of a solution of peptide 11-G $(0.00086 \mathrm{M})$ in $\left(\mathrm{CD}_{3}\right)_{2} \mathrm{SO}$. Resonances attributable to the $12 \mathrm{NH}$ groups (10 backbone and 2 side chain) are observed. Singlets, doublets, and triplets are identified by the labels $\mathrm{S}_{n}, \mathrm{D}_{n}$ and $\mathrm{T}_{n}$, respectively, with the subscripts indicating the order of appearance from low-field in $\left(\mathrm{CD}_{3}\right)_{2} \mathrm{SO}$. Assignments of doublets to Leu(3) and Leu(6) $\left(D_{5}, D_{7}\right)$ and $\operatorname{Val}(9)\left(D_{6}\right)$ were made on the basis of decoupling experiments, as described earlier (Iqbal \& Balaram, 1981b). An unambiguous distinction between the two Leu residues is not possible. The triplet $\left(T_{2}\right)$ can be unequivocally assigned to Gly(5) while the Gln(1) side-chain carboxamide NH groups $\left(S_{9}\right.$ and $\left.S_{12}\right)$ are assigned on the basis of their broadening and disappearance at high temperatures. This feature has been noted in earlier studies of model Gln peptides (Zanacchi \& Moore, 1980). The urethane $\mathrm{NH}$ of $\mathrm{G} \ln (1)$ was assigned to the only doublet $\left(\mathrm{D}_{10}\right)$ that broadened at high temperature in $\left(\mathrm{CD}_{3}\right)_{2} \mathrm{SO}$, a property frequently observed for the urethane $\mathrm{NH}$ in a variety of peptides (Iqbal et al., 1981; M. Iqbal, unpublished results). The remaining five singlets $\left(S_{1}, S_{3}, S_{4}\right.$, $S_{8}$, and $S_{11}$ ) were then assigned to the Aib residues. In our earlier study of the conformation of 11-G, $S_{1}$ was assigned to the only non-hydrogen-bonded Aib residue in the $3_{10}$ helical structure, i.e., Aib(2) (Iqbal \& Balaram, 1981b).

The $\mathrm{NH}$ resonances of the peptide 11- $\mathrm{A}$ in $\left(\mathrm{CD}_{3}\right)_{2} \mathrm{SO}$ $(0.0013 \mathrm{M})$ are shown in Figure $2 \mathrm{~b}$. Assignments of reso-
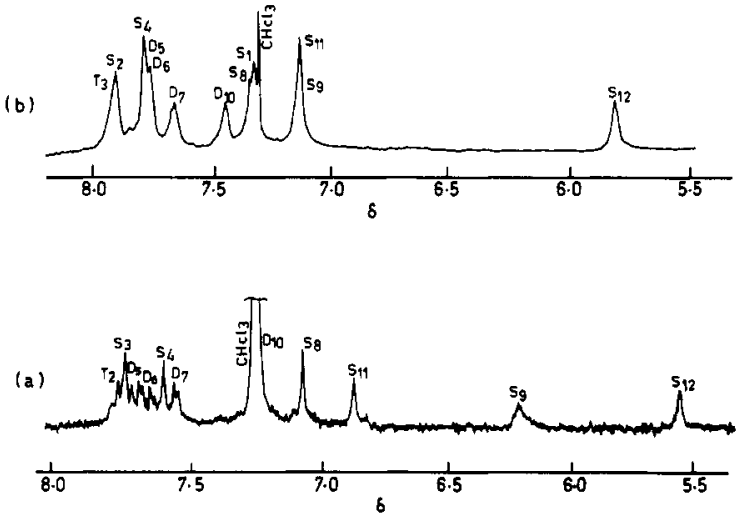

FIGURE 3: Partial 270-MHz ${ }^{1} \mathrm{H}$ NMR spectra (NH region) of 11-G at different concentrations in $\mathrm{CDCl}_{3}$ : (a) $0.00086 \mathrm{M}$; (b) $0.043 \mathrm{M}$.

(b)
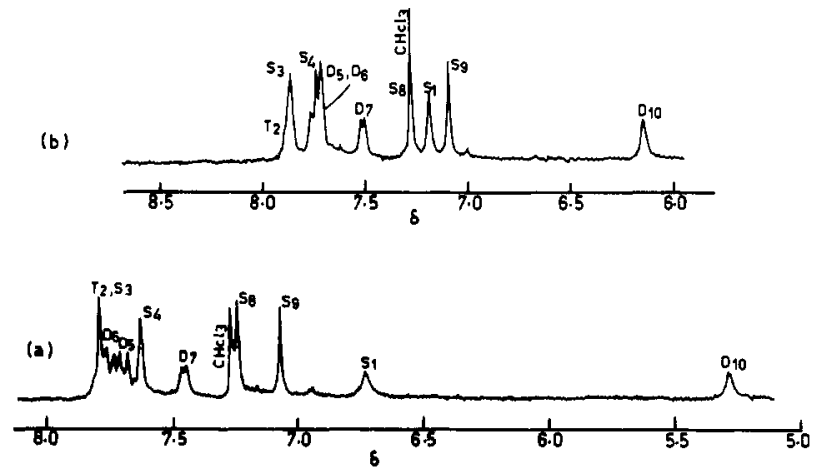

FIGURE 4: Partial 270-MHz 'H NMR spectra (NH region) of 11-A in $\mathrm{CDCl}_{3}$ : (a) $0.0018 \mathrm{M}$; (b) $0.045 \mathrm{M}$.

nances are based on those for 11-G. The Ala(1) NH (urethane, $\mathrm{D}_{10}$ ) was unambiguously identified by its high-field position in $\mathrm{CDCl}_{3}$, a characteristic of urethane $\mathrm{NH}$ groups (Nagaraj et al., 1979; Nagaraj \& Balaram, 1981; Iqbal \& Balaram, 1981a). The corresponding resonance in $\left(\mathrm{CD}_{3}\right)_{2} \mathrm{SO}$ was identified by solvent titration experiments in $\mathrm{CDCl}_{3}-(\mathrm{C}$ $\left.\mathrm{D}_{3}\right)_{2} \mathrm{SO}$ mixtures. Figures 3 and 4 show the $\mathrm{NH}$ resonances of peptides 11-G and 11-A, respectively, in $\mathrm{CDCl}_{3}$ at the extreme concentrations used in this study. For 11-G, wellresolved resonances were observed for all $12 \mathrm{NH}$ protons at low concentrations. Some spectral overlap $\left(T_{2}\right.$ and $S_{3} ; D_{5}$ and $D_{6} ; S_{8}$ and $S_{1} ; S_{11}$ and $S_{9}$ ) was observed at high concentrations. However, separation of such overlapping peaks could be obtained in temperature variation experiments, permitting as- 

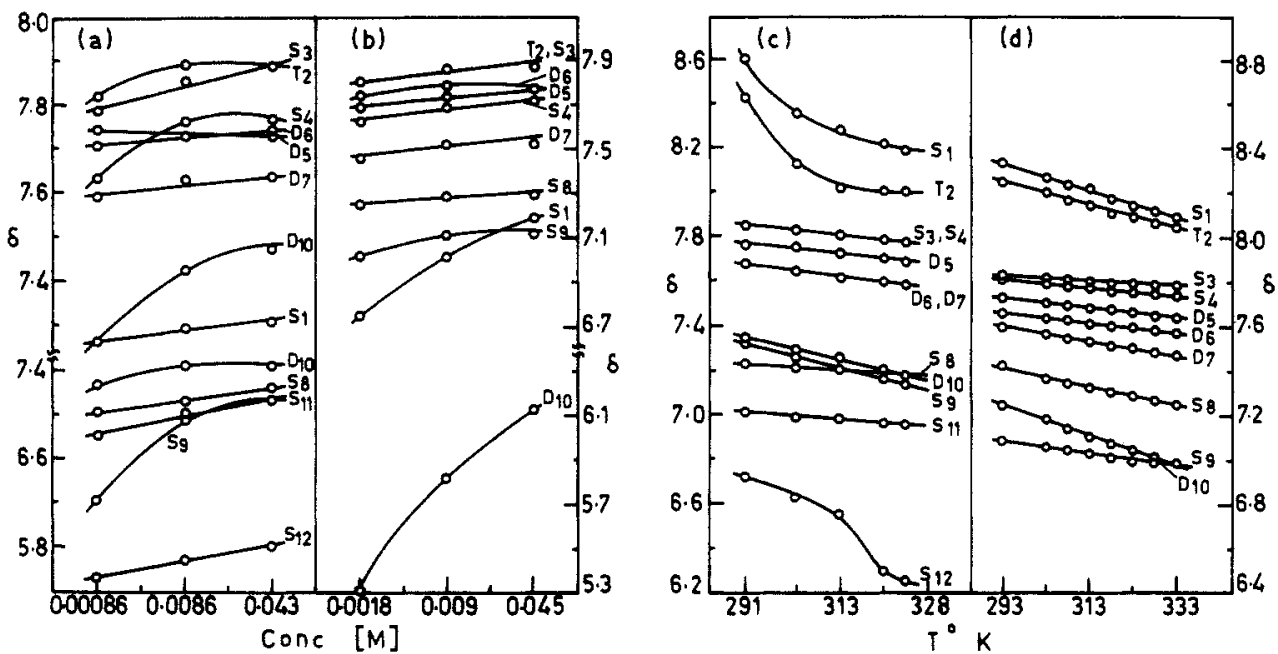

FIGURE 5: (a) Concentration dependence of $\mathrm{NH}$ chemical shifts for 11-G in $\mathrm{CDCl}_{3}$. (b) Concentration dependence of $\mathrm{NH}$ chemical shifts for 11-A in $\mathrm{CDCl}_{3}$. (c) Temperature dependence of $\mathrm{NH}$ chemical shifts for 11-G $(0.00086 \mathrm{M})$ in $\left(\mathrm{CD}_{3}\right)_{2} \mathrm{SO}$. (d) Temperature dependence of NH chemical shifts for 11-A $(0.0013 \mathrm{M})$.

Table I: NMR Parameters of NH Groups in Peptide 11-G

\begin{tabular}{|c|c|c|c|c|c|c|c|c|}
\hline \multirow[b]{2}{*}{$\mathrm{NH}^{a}$} & \multicolumn{3}{|c|}{$\begin{array}{c}\mathrm{d} \delta / \mathrm{d} T\left(\mathrm{ppm} / /^{\circ} \mathrm{C}\right) \times 10^{3} \\
\text { for } \mathrm{CDCl}_{3} \text { at }\end{array}$} & \multirow[b]{2}{*}{$\Delta \delta^{b}$} & \multicolumn{3}{|c|}{$\begin{array}{c}\mathrm{d} \delta / \mathrm{d} T\left(\mathrm{ppm} /{ }^{\circ} \mathrm{C}\right) \times 10^{3} \\
\quad \text { for }\left(\mathrm{CD}_{3}\right)_{2} \mathrm{SO} \text { at }\end{array}$} & \multirow[b]{2}{*}{$\Delta \delta^{b}$} \\
\hline & 0.00086 & $0.0086 \mathrm{M}$ & $\overline{0.043 \mathrm{M}}$ & & $0.00086 \mathrm{M}$ & $0.0086 \mathrm{M}$ & $0.043 \mathrm{M}$ & \\
\hline $\mathrm{S}_{1}[\mathrm{Aib}(2)]$ & 1.7 & 5.5 & 5.0 & 0.042 & $c$ & 5.3 & 5.5 & -0.213 \\
\hline $\mathrm{T}_{2}[\mathrm{Gly}(5)]$ & $c$ & 4.0 & $c$ & 0.063 & $c$ & 4.8 & 5.0 & -0.234 \\
\hline $\mathrm{S}_{3}(\mathrm{Aib})$ & $c$ & 3.0 & $c$ & 0.090 & 2.1 & 1.3 & 1.1 & -0.027 \\
\hline $\mathrm{S}_{4}$ (Aib) & 1.9 & 3.5 & 2.0 & 0.125 & 2.1 & 2.0 & 1.7 & -0.050 \\
\hline $\mathrm{D}_{\mathrm{s}}(\mathrm{Leu})$ & 3.0 & 1.9 & 2.2 & -0.008 & 1.9 & 1.8 & 2.0 & -0.032 \\
\hline$D_{6}[\mathrm{Val}(9)]$ & 3.5 & 2.0 & 2.2 & 0.032 & 2.2 & 2.1 & 1.9 & -0.011 \\
\hline $\mathrm{D}_{7}(\mathrm{Leu})$ & 2.9 & 3.0 & 2.3 & 0.039 & 2.1 & 2.6 & 3.0 & -0.090 \\
\hline$S_{8}[\operatorname{Aib}(7)]$ & 0.3 & 1.3 & 1.7 & 0.241 & 1.2 & 2.8 & 3.3 & 0.127 \\
\hline$S_{9}$ (trans) & $c$ & 9.0 & $c$ & 0.897 & 4.2 & 3.6 & 4.0 & -0.039 \\
\hline$D_{10}[G \ln (1)]$ & $c$ & 8.5 & $c$ & 0.159 & 6.1 & 5.4 & 6.1 & -0.077 \\
\hline $\mathrm{S}_{11}$ (Aib) & 2.3 & 1.3 & 1.5 & 0.243 & 1.2 & 1.8 & 2.3 & 0.053 \\
\hline $\mathrm{S}_{12}$ (cis) & 2.7 & 4.0 & 4.3 & 0.235 & $c$ & 4.8 & 5.0 & 0.109 \\
\hline
\end{tabular}

${ }^{a}$ Assignments made as discussed earlier (Iq bal \& Balaram, 1981b). $S_{9}$ and $S_{12}$ are the side-chain NH protons of Gln, trans and cis to the $C O$ group, respectively. $b \Delta \delta$ is the difference in chemical shift between the highest and lowest concentration values. Negative values indicate upfield shifts with increasing concentration. ${ }^{c} \mathrm{~d} \delta / \mathrm{d} T$ values were not obtained, as the $\delta$ vs. $T$ plots are nonlinear.

Table II: NMR Parameters of NH Groups in Peptide 11-A

\begin{tabular}{|c|c|c|c|c|c|c|c|}
\hline \multirow[b]{2}{*}{$\mathrm{NH}^{a}$} & \multicolumn{2}{|c|}{$\begin{array}{c}\mathrm{d} \delta / \mathrm{d} T\left(\mathrm{ppm} /{ }^{\circ} \mathrm{C}\right) \times 10^{3} \\
\text { for } \mathrm{CDCl}_{3} \text { at } \\
\end{array}$} & \multirow[b]{2}{*}{$\Delta \delta^{b}$} & \multicolumn{3}{|c|}{$\begin{array}{l}\mathrm{d} \delta / \mathrm{d} T\left(\mathrm{ppm} /{ }^{\circ} \mathrm{C}\right) \times 10^{3} \\
\text { for }\left(\mathrm{CD}_{3}\right)_{2} \mathrm{SO} \text { at }\end{array}$} & \multirow[b]{2}{*}{$\Delta \delta^{b}$} \\
\hline & $0.0018 \mathrm{M}$ & $0.045 \mathrm{M}$ & & 0.0013 & $0.009 \mathrm{M}$ & $0.045 \mathrm{M}$ & \\
\hline$S_{1}[\operatorname{Aib}(2)]$ & 4.7 & 5.8 & 0.452 & 6.1 & 6.0 & 6.4 & -0.009 \\
\hline $\mathrm{T}_{2}[\mathrm{Gly}(5)]$ & 3.1 & 3.1 & 0.084 & 5.2 & 5.3 & 5.7 & -0.001 \\
\hline $\mathrm{S}_{3}$ & 3.1 & 3.1 & 0.084 & 0.9 & 1.1 & 1.0 & 0.007 \\
\hline$S_{4}^{3}$ & 2.1 & 2.0 & 0.099 & 1.9 & 2.5 & 2.3 & 0.007 \\
\hline $\mathrm{D}_{5}$ (Leu) & 2.8 & 1.8 & 0.070 & 2.3 & 2.4 & 2.5 & -0.001 \\
\hline$D_{6}[\mathrm{Val}(9)]$ & 2.4 & 1.8 & 0.018 & 2.3 & 2.3 & 2.5 & 0.004 \\
\hline $\mathrm{D}_{7}$ (Leu) & 3.8 & 3.3 & 0.062 & 3.1 & 3.0 & 3.4 & -0.005 \\
\hline $\mathrm{S}_{8}[\mathrm{Aib}(7)]$ & 1.6 & 1.5 & 0.044 & 4.1 & 3.7 & 4.0 & -0.024 \\
\hline$S_{9}$ & 0.2 & 0.9 & 0.019 & 2.4 & 2.2 & 2.5 & -0.008 \\
\hline $\mathrm{D}_{10}[\mathrm{Ala}(1)]$ & 5.2 & 7.8 & 0.840 & 7.7 & 7.3 & 8.4 & -0.015 \\
\hline
\end{tabular}

${ }^{a}$ Assignments made as described in text, by comparison with 11-G. ${ }^{b} \Delta \delta$ is defined in footnote to Table $I$.

signments. In 11-A, exceedingly well-resolved resonances were observed over the entire concentration range. All assignments in $\mathrm{CDCl}_{3}$ are based on solvent titration experiments. The $\mathrm{G} \ln (1) \mathrm{NH}\left(\mathrm{D}_{10}\right)$ in 11-G appears at abnormally low field in $\mathrm{CDCl}_{3}$, over the entire concentration range, supporting our earlier suggestion that this $\mathrm{NH}$ group may be involved in a side chain-backbone hydrogen bond with the $\mathrm{CO}$ group of the carboxamide side chain of Gln(1) (Iqbal \& Balaram, 1981b). The chemical shifts of the various $\mathrm{NH}$ resonances were determined as a function of concentration in order to monitor the effect of peptide association for 11-G and 11-A. Repre- sentative results in $\mathrm{CDCl}_{3}$ are summarized in Figure 5a,b. The differences in chemical shifts $(\Delta \delta)$ at the highest and lowest concentrations studied are presented in Tables $I$ and II for 11-G and 11-A, respectively.

Temperature Dependence of Chemical Shifts. Intramolecularly hydrogen-bonded $\mathrm{NH}$ groups are often delineated on the basis of temperature and solvent dependences of NH chemical shifts (Wuthrich, 1976). Low-tempeature coefficients $\left(\mathrm{d} \delta / \mathrm{d} T<4 \times 10^{-3} \mathrm{ppm} /{ }^{\circ} \mathrm{C}\right)$ in hydrogen bond accepting solvents, like $\left(\mathrm{CD}_{3}\right)_{2} \mathrm{SO}$, are characteristic of solvent shielded and/or intramolecularly hydrogen-bonded $\mathrm{NH}$ 
groups, while $\mathrm{d} \delta / \mathrm{d} T$ values $>6 \times 10^{-3} \mathrm{ppm} /{ }^{\circ} \mathrm{C}$ are generally assigned to solvent-exposed, free NH groups (Wuthrich, 1976; Hruby, 1974; Venkatachalapathi \& Balaram, 1981a,b). Temperature coefficient data in relatively nonpolar, poorly hydrogen-bonding solvents like $\mathrm{CDCl}_{3}$ may also provide valuable information on peptide structure and aggregation. Stevens et al. (1980) suggest that low $\mathrm{d} \delta / \mathrm{d} T$ values $(<3 \times$ $10^{-3} \mathrm{ppm} /{ }^{\circ} \mathrm{C}$ ) in $\mathrm{CDCl}_{3}$ may correspond to either strongly solvent-shielded or completely exposed NH groups. High $\mathrm{d} \delta / \mathrm{d} T$ values, on the other hand, may be interpreted as indicative of $\mathrm{NH}$ groups participating in intermolecular hydrogen bonding or in weak intramolecular interactions, both of which are disrupted with increasing temperature. A detailed NMR analysis of hydrogen-bonded peptide structure should be facilitated by a comparison of the concentration and solvent dependences of $d \delta / d T$ values for $\mathrm{NH}$ groups. The utility of such studies in approaching the problem of peptide association has been explored in the case of 1-10 suzukacillin fragment (M. Iqbal and P. Balaram, unpublished results). A detailed analysis for the peptides 11-G and 11-A is outlined below. Temperature dependences of $\mathrm{NH}$ chemical shifts were measured over the concentration range $0.043-0.00086 \mathrm{M}$ in $\mathrm{CDCl}_{3}$ and $\left(\mathrm{CD}_{3}\right)_{2} \mathrm{SO}$. In $\left(\mathrm{CD}_{3}\right)_{2} \mathrm{SO}, 11-\mathrm{G}$ at low concentrations $(0.00086 \mathrm{M})$ shows pronounced curvature of the $\delta$ vs. $T$ plots for resonances $S_{1}[\mathrm{Aib}(2)], \mathrm{T}_{2}[\mathrm{Gly}(5)]$, and $\mathrm{S}_{12}$ [the side-chain amide hydrogen of $\mathrm{Gln}(1)$, cis to the $\mathrm{CO}$ group] (Figure 5c). At $0.043 \mathrm{M}$, all NH groups show linear temperature dependences. Our earlier study established linear behavior of the $\mathrm{NH}$ resonances of $11-\mathrm{G}$ at $0.0086 \mathrm{M}$ in $\left(\mathrm{CD}_{3}\right)_{2} \mathrm{SO}$ (Iqbal \& Balaram, 1981b). At low concentration in $\mathrm{CDCl}_{3}$, the resonances $\mathrm{S}_{9}$ (Gln side-chain amide hydrogen trans to the carbonyl group) and $D_{10}[G \ln (1)]$ show a nonlinear temperature dependence of chemical shifts. At $0.043 \mathrm{M}$, the curve for $D_{10}$ is significantly more linear, while that of $S_{9}$ still exhibits a nonlinear temperature dependence. Further, two overlapping $\mathrm{NH}$ resonances $\left(\mathrm{T}_{2}\right)$ and one $\mathrm{Aib} \mathrm{NH}\left(\mathrm{S}_{3}\right)$ show slight deviations from linearity. The upfield shifts with increasing temperature are very much smaller for $S_{3}$ and $T_{2}$ as compared to $S_{9}$ and $D_{10}$. Deviations from linearity may arise due to structural changes with temperature, resulting in the exposure of an originally solvent-shielded NH group. The $\mathrm{d} \delta / \mathrm{d} T$ values for the various $\mathrm{NH}$ resonances in $11-\mathrm{G}$ at different concentrations in $\mathrm{CDCl}_{3}$ and $\left(\mathrm{CD}_{3}\right)_{2} \mathrm{SO}$ are presented in Table I. Seven backbone NH groups $\left(S_{3}, S_{4}, D_{5}, D_{6}, D_{7}\right.$, $\mathrm{S}_{8}$, and $\left.\mathrm{S}_{11}\right)$ show low $\mathrm{d} \delta / \mathrm{d} T$ values $\left(<4 \times 10^{-3} \mathrm{ppm} /{ }^{\circ} \mathrm{C}\right)$ in $\left(\mathrm{CD}_{3}\right)_{2} \mathrm{SO}$, over the entire range of concentrations. This suggests the involvement of seven $\mathrm{NH}$ groups in intramolecular hydrogen bonding and further supports the contention that the $3_{10}$ helical conformation proposed earlier (Iqbal \& Balaram, $1981 \mathrm{~b}$ ) is largely unaffected by aggregation effects.

All NH resonances in 11-A show linear temperature dependences of chemical shifts in both $\mathrm{CDCl}_{3}$ and $\left(\mathrm{CD}_{3}\right)_{2} \mathrm{SO}$, over the entire concentration range studied $(0.0018-0.045 \mathrm{M})$. Figure 5d shows a representative set of data. Further, for 11-A in $\left(\mathrm{CD}_{3}\right)_{2} \mathrm{SO}$, seven $\mathrm{NH}$ groups $\left(\mathrm{S}_{3}, \mathrm{~S}_{4}, \mathrm{D}_{5}, \mathrm{D}_{6}, \mathrm{D}_{7}, \mathrm{~S}_{8}\right.$, and $\mathrm{S}_{9}$ ) have relatively low $\mathrm{d} \delta / \mathrm{d} T$ values $\left(<4 \times 10^{-3} \mathrm{ppm} /{ }^{\circ} \mathrm{C}\right)$ at all concentrations (Table II). Figure 6 shows the dependence of $\mathrm{NH}$ chemical shifts in 11-A on solvent composition in $\mathrm{CDCl}_{3}-\left(\mathrm{CD}_{3}\right)_{2} \mathrm{SO}$ mixtures. Increasing concentration of the strongly hydrogen bond accepting solvent $\left(\mathrm{CD}_{3}\right)_{2} \mathrm{SO}$ perturbs significantly only resonances $S_{1}$ and $D_{10}$ while the others are insensitive. These results together with the $\mathrm{d} \delta / \mathrm{d} T$ values in Table II strongly suggest that $\mathbf{1 1 - A}$ adopts a largely $3_{10}$ helical conformation, stabilized by seven strong intramolecular $4 \rightarrow 1$ hydrogen bonds. This is analogous to the structure suggested

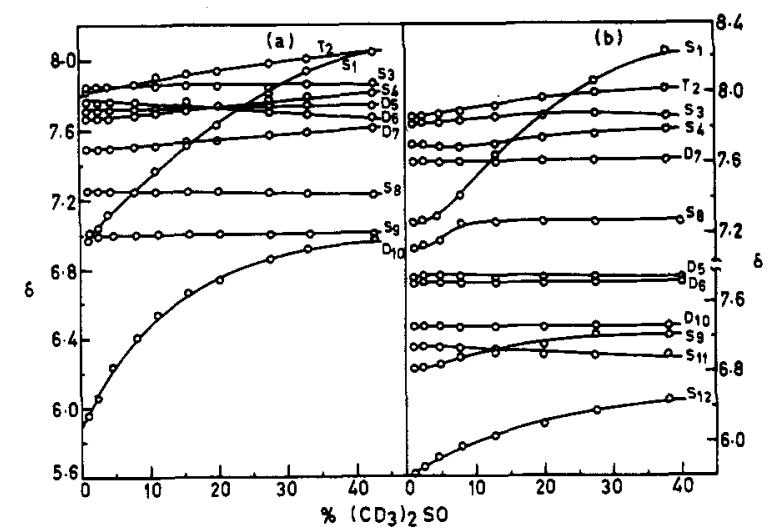

FIGURE 6: Solvent dependence of $\mathrm{NH}$ chemical shifts in $\mathrm{CDCl}_{3}-$ $\left(\mathrm{CD}_{3}\right)_{2} \mathrm{SO}$ mixtures: (a) 11-A, $0.009 \mathrm{M}$; (b) 11-G, $0.0086 \mathrm{M}$.

for 11-G (Iqbal \& Balaram, 1981b) and leads to the conclusion that replacement of $\mathrm{G} \ln (1)$ by Ala is without any major effect on the backbone conformation of the peptide. The solventexposed NH groups in 11-A are $\mathrm{Aib}(2)\left(S_{1}\right)$ and $\mathrm{Ala}(1)\left(D_{10}\right)$. The $\operatorname{Gly}(5) \mathrm{NH}\left(\mathrm{T}_{2}\right)$ in 11-A has a relatively high $\mathrm{d} \delta / \mathrm{d} T$ value in $\left(\mathrm{CD}_{3}\right)_{2} \mathrm{SO}\left[(5.2-5.7) \times 10^{-3} \mathrm{ppm} /{ }^{\circ} \mathrm{C}\right]$ but shows only a small solvent shift in the $\mathrm{CDCl}_{3}-\left(\mathrm{CD}_{3}\right)_{2} \mathrm{SO}$ system. As proposed earlier for 11-G (Iqbal \& Balaram, 1981b), this NH group may participate in a weaker interaction. In both peptides, the Gly-Leu segment is probably more flexible than the rest of the chain. One $\mathrm{Aib} \mathrm{NH}\left(\mathrm{S}_{8}\right)$ shows a comparatively high $d \delta / d T$ value in $\left(C D_{3}\right)_{2} S O$ but a rather low value in $\mathrm{CDCl}_{3} . \mathrm{S}_{8}$ may be assigned to $\mathrm{Aib}(7) \mathrm{NH}$, since the Gly-Leu type III $\beta$ turn could be destabilized in a polar solvent like $\left(\mathrm{CD}_{3}\right)_{2} \mathrm{SO}$, resulting in disruption of the $4 \rightarrow 1$ hydrogen bond between $\mathrm{Aib}(4) \mathrm{CO}$ and the $\mathrm{NH}$ of $\mathrm{Aib}(7)$. In nonpolar media $\left(\mathrm{CDCl}_{3}\right)$, the integrity of the $3_{10}$ helical structure is probably fully maintained. The corresponding $\mathrm{Aib}(7) \mathrm{NH}$ in $11-\mathrm{G}\left(\mathbf{S}_{8}\right)$ may be assigned similarly, on the basis of its high $\mathrm{d} \delta / \mathrm{d} T$ value in $\left(\mathrm{CD}_{3}\right)_{2} \mathrm{SO}$ at high concentrations. Interestingly, this resonance exhibits a very large concentration dependence of $\mathrm{d} \delta / \mathrm{d} T$ in $\left(\mathrm{CD}_{3}\right)_{2} \mathrm{SO}$, with an increase from $1.2 \times 10^{-3} \mathrm{ppm} /{ }^{\circ} \mathrm{C}$ at $0.00086 \mathrm{M}$ to $3.3 \times 10^{-3} \mathrm{ppm} /{ }^{\circ} \mathrm{C}$ at $0.043 \mathrm{M}$.

A further point of comparison between 11-G and 11-A may be made from the solvent titration curves in Figure 6. In 11-A, the fully solvent-exposed hydrogens, $S_{1}$ and $D_{10}$, show large, monotonic downfield shifts with increasing $\left(C_{3}\right)_{2} S O$ concentration, while all the other $\mathrm{NH}$ groups are relatively insensitive. In 11-G, $\mathrm{S}_{1}[\mathrm{Aib}(2) \mathrm{NH}]$ shows a large solvent shift at high $\left(\mathrm{CD}_{3}\right)_{2} \mathrm{SO}$ concentrations but is insensitive up to about $5 \%\left(\mathrm{CD}_{3}\right)_{2} \mathrm{SO}$. Similar discontinuous behavior is also observed for $S_{8}$. These results are suggestive of solvent-dependent structural changes and have earlier been attributed, in the case of $S_{1}$, to breaking of side chain-backbone hydrogen bonds to the $\mathrm{CO}$ of the Gin side chain. The behavior of $\mathbf{S}_{8}$ probably arises from destabilization of the Gly-Leu type III $\beta$ turn.

\section{Discussion}

Highly folded $3_{10}$ helical conformations have been suggested for the 1-10 and 11-21 suzukacillin fragments (Iqbal \& Balaram, 1981a,b) on the basis of ${ }^{1} \mathrm{H}$ NMR studies, using solvent titration and temperature coefficient data for delineating hydrogen-bonded NH groups. These structural proposals were also based on the known propensity of Aib residues to favor type III $\beta$-turn or $3_{10}$ helical structures (Nagaraj et al., 1979; Rao et al., 1980; Venkatachalapathi \& Balaram, 1981b; Venkatachalapathi et al., 1981; Nagaraj \& Balaram, 1981a). The present study was designed to probe the modes of peptide association in both polar and nonpolar solvents and 


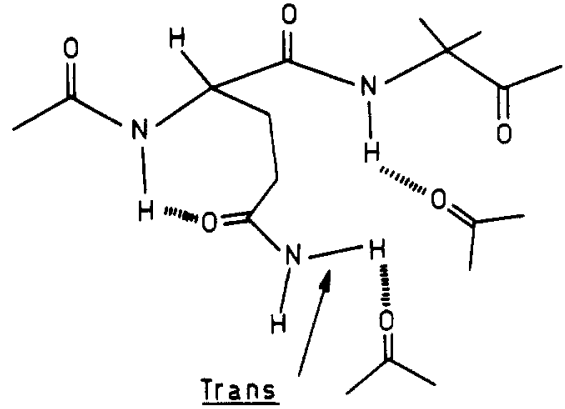

(a)

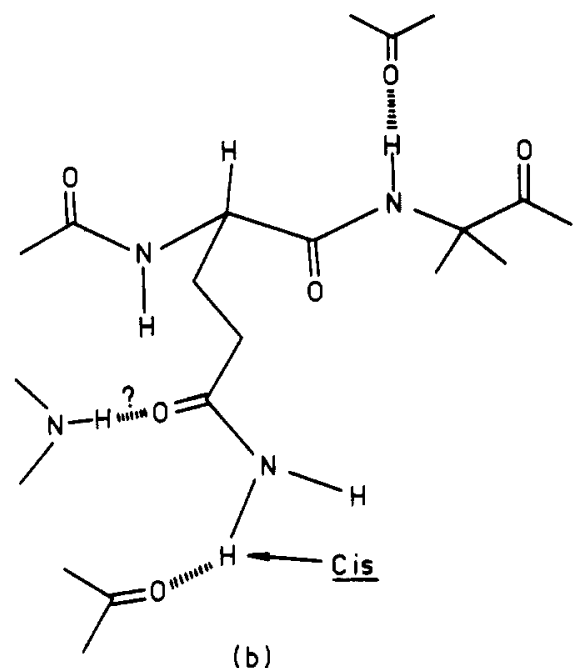

(b)

FIGURE 7: Schematic representation of inter- and intramolecular hydrogen bonding involving the Gln side chain. (a) Association favored in $\mathrm{CDCl}_{3}$ with trans carboxamide $\mathrm{NH}$ participating in an intermolecular hydrogen bond. (b) Association postulated in $\left(\mathrm{CD}_{3}\right)_{2} \mathrm{SO}$. Cis carboxamide $\mathrm{NH}$ participates in intermolecular hydrgen bonding.

to evaluate the role of the Gln residue in stabilizing peptide aggregates.

The results described above establish that replacement of Gln(1) by Ala(1) does not appreciably alter backbone conformation. Both peptides 11-A and 11-G adopted folded, $3_{10}$ helical structures stabilized by at least seven intramolecular $4 \rightarrow 1$ hydrogen bonds. In $11-\mathrm{A}$, the $\mathrm{d} \delta / \mathrm{d} T$ values, for the intramolecularly hydrogen-bonded $\mathrm{NH}$ groups, are relatively insensitive to changes in concentration in $\mathrm{CDCl}_{3}$ and (C$\left.\mathrm{D}_{3}\right)_{2} \mathrm{SO}$. 11-G behaves similarly except for resonance $S_{8}$ [Aib(7) NH]. This suggests that even if peptide association occurs, the backbone conformations remain largely unaltered. Further support for this conclusion is obtained from studies which establish that these shielded NH groups show very little concentration dependence of chemical shifts in both peptides.

The solvent-exposed (free) NH groups in 11-A and 11-G, however, do exhibit concentration dependence of chemical shifts and temperature coefficients in both solvents. For 11-A in $\mathrm{CDCl}_{3}$, both free $\mathrm{NH}$ groups $\mathrm{S}_{1}[\mathrm{Aib}(2)]$ and $\mathrm{D}_{10}$ [Ala(1)] show increases in $\mathrm{d} \delta / \mathrm{d} T$ values with increasing temperature. These resonances also show large downfield shifts with increasing peptide concentration in $\mathrm{CDCl}_{3}$, in marked contrast to the intramolecularly hydrogen-bonded NH groups. These observations suggest that the helical 11-A molecules associate by intermolecular hydrogen bonding involving exposed $\mathrm{NH}$ groups. The increase in $\mathrm{d} \delta / \mathrm{d} T$ values in $\mathrm{CDCl}_{3}$ with concentration is consistent with an increase in the population of associated species (Stevens et al., 1980; M. Iqbal and P. Balaram, unpublished results). In $\left(\mathrm{CD}_{3}\right)_{2} \mathrm{SO}$, the solvent-exposed $\mathrm{NH}$ groups also do not show any concentration dependence of chemical shifts or $\mathrm{d} \delta / \mathrm{d} T$ values, suggesting that in polar media peptide association is not appreciable.

For 11-G in $\mathrm{CDCl}_{3}$, the solvent-exposed backbone $\mathrm{NH}$ group $S_{1}[\mathrm{Aib}(2)]$ and $D_{10}[\mathrm{Gin}(1)]$ show relatively small downfield shifts with increasing concentration. As noted earlier, the urethane $\mathrm{NH}\left(\mathrm{D}_{10}\right)$ appears at abnormally lowfield in $\mathrm{CDCl}_{3}$ over the entire concentration range. $\mathrm{D}_{10}$ also does not show any concentration dependence of $\mathrm{d} \delta / \mathrm{d} T$ values in $\mathrm{CDCl}_{3}$. We propose that $\mathrm{G} \ln (1) \mathrm{NH}\left(\mathrm{D}_{10}\right)$ is involved in a hydrogen bond with the $\mathrm{CO}$ group of the GIn side chain over the entire concentration range studied. At low concentration $(0.00086 \mathrm{M})$, species in which $\mathrm{Aib}(2) \mathrm{NH}\left(\mathrm{S}_{1}\right)$ is hydrogen bonded to the GIn side-chain $\mathrm{CO}$ are also populated. With increasing concentration, peptide helices aggregate, with Aib(2) NH becoming involved in intermolecular hydrogen bonding. The side chain-backbone interaction in which $\mathrm{Gln}(1)$ $\mathrm{NH}$ participates is retained even in the associated species. This interpretation accounts for the low $\Delta \delta$ value for $\mathrm{S}_{1}$ (Table I) and also its concentration-dependent $\mathrm{d} \delta / \mathrm{d} T$ value. The side-chain carboxamide proton $S_{9}$ (trans) shows a large downfield shift with increasing concentration in $\mathrm{CDCl}_{3}$, whereas $S_{12}$ (cis) is much less concentration dependent. These results suggest that peptide association occurs via hydrogen bonds involving $S_{9}$, while $S_{12}$ is relatively free. The nonlinearity in the $\delta$ vs. $T$ curves for $\mathrm{S}_{9}$ would then arise from dissociation of aggregated species at higher temperatures.

For 11-G in $\left(\mathrm{CD}_{3}\right)_{2} \mathrm{SO}$, of the exposed backbone $\mathrm{NH}$ groups, $S_{1}$ shows a large concentration dependence of the shape of the $\delta$ vs. $T$ curves. At low concentration $(0.00086 \mathrm{M})$, there are large deviations from linearity which are abolished at higher peptide concentration $(\geq 0.0086 \mathrm{M}) . \mathrm{D}_{10}$ exhibits a linear $\delta$ vs. $T$ curve, and the $\mathrm{d} \delta / \mathrm{d} T$ values are unaffected by concentration. The results are consistent with the involvement of $\mathrm{S}_{1}$ [Aib(2) $\mathrm{NH}$ ] in intermolecular association. The low concentration dependence of chemcal shifts in this solvent, as compared to $\mathrm{CDCl}_{3}$, is reasonable since in the free molecules the exposed $\mathrm{NH}$ groups would bond to $\left(\mathrm{CD}_{3}\right)_{2} \mathrm{SO}$ while in associated species they would interact with a $\mathrm{CO}$ group. The chemical shift of the side-chain $\mathrm{NH} \mathrm{S}_{9}$ (trans) shows a linear temperature dependence, and the $\mathrm{d} \delta / \mathrm{d} T$ values are concentration independent. On the contrary, $S_{12}$ (cis) shows nonlinear temperature dependence of chemical shift at low concentrations $(0.00086 \mathrm{M})$ in $\left(\mathrm{CD}_{3}\right)_{2} \mathrm{SO}$. At higher concentrations, the $\delta$ vs. $T$ curves are linear, and the $\mathrm{d} \delta / \mathrm{d} T$ values are high, characteristic of an exposed NH group. It appears that aggregates in $\left(\mathrm{CD}_{3}\right)_{2} \mathrm{SO}$ may be stabilized by hydrogen bonding involving the cis carboxamide $\mathrm{NH}\left(\mathrm{S}_{12}\right)$, in contrast to $\mathrm{CDCl}_{3}$ where the trans $\mathrm{NH}\left(\mathrm{S}_{9}\right)$ is involved. This may arise from the fact that in $\mathrm{CDCl}_{3}$ the aggregates formed retain the hydrogen bond between $\mathrm{G} \ln (1) \mathrm{NH}$ and the $\mathrm{CO}$ group of the Gln side chain. In such a situation, the trans $\mathrm{NH}$ would be sterically more accessible. The modes of intermolecular association suggest in the two solvents are schematically illustrated in Figure 7.

The present study establishes that the suzukacillin fragment 11-G aggregates over the concentration range 0.00086 (1 $\mathrm{mg} / \mathrm{mL})-0.0086 \mathrm{M}(10 \mathrm{mg} / \mathrm{mL})$ in $\left(\mathrm{CD}_{3}\right)_{2} \mathrm{SO}$. In $\mathrm{CDCl}_{3}$, aggregated species appear to be present even at the lowest concentration studied $(0.00086 \mathrm{M})$. The mode of aggregation in the two solvents differs but is mediated by intermolecular 


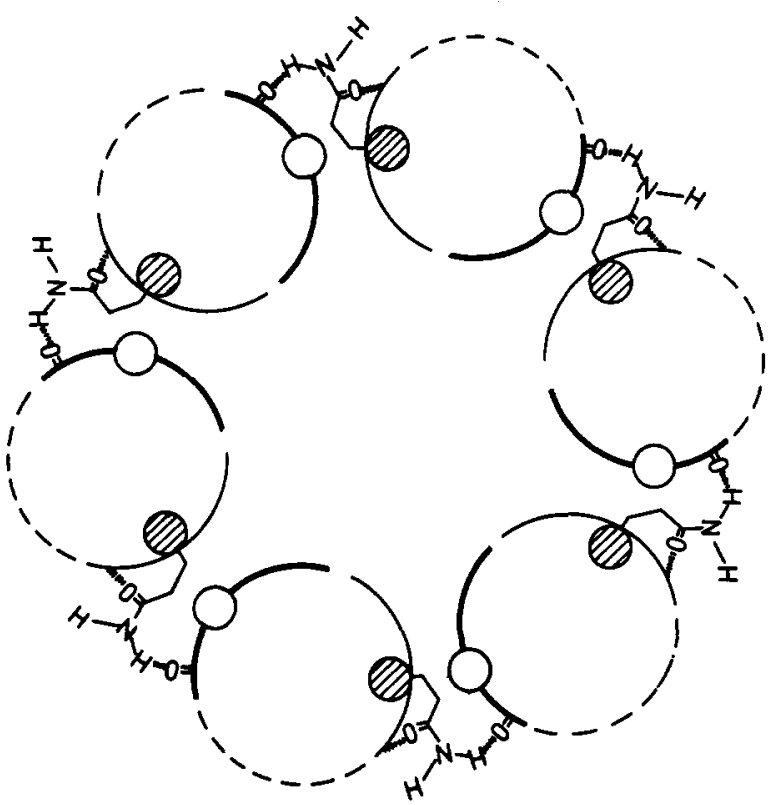

FIGURE 8: Proposed model for a hexameric aggregate of channelforming polypeptides like suzukacillin or alamethcin.

hydrogen bonds involving the solvent-exposed Aib(1) $\mathrm{NH}$ and Gln side-chain carboxamide protons. Our results suggest that peptide association is strongly favored in nonpolar media. In the case of 11-A and 11-G, aggregation does not affect backbone conformation, and the molecules probably associate as rigid helical rods. This may, in general, be true for the stereochemically rigid Aib-containing peptides. However, in other cases, aggregation could, in principle, involve large changes in backbone conformation. ${ }^{1} \mathrm{H}$ NMR studies of peptides in organic solvents should therefore also address the possible role of aggregation and the consequent effects on NMR parameters. The differences in the behavior of 11-A and 11-G clearly establish an important role for the $G \ln (1)$ side chain in peptide association. It is likely that the aggregation via intermolecular hydrogen bonding between the Gln side chain of one molecule and a backbone amide group of another may be an important factor in stabilizing channelforming peptide aggregates in the apolar phase of biological membranes.

Two interesting features of the data presented merit comment. The Gly $(5) \mathrm{NH}\left(\mathrm{T}_{2}\right)$ shows nonlinear $\delta$ vs. $T$ plots for 11-G in $\mathrm{CDCl}_{3}$ at all concentrations studied (figure not shown) and also at $0.00086 \mathrm{M}$ in $\left(\mathrm{CD}_{3}\right)_{2} \mathrm{SO}$ (Figure $5 \mathrm{c}$ ). $\mathrm{S}_{8}$ [Aib(7)] $\mathrm{NH}$ shows a significant increase in $\mathrm{d} \delta / \mathrm{d} T$, with the peptide concentration in $\left(\mathrm{CD}_{3}\right)_{2} \mathrm{SO}$. We speculate that these anomalies associated with Gly(5) and $\mathrm{Aib}(7)$ may arise due to involvement of the central segment, -Aib(4)-Gly(5)-Leu(6)-Aib(7)-Pro(8)-, in peptide aggregation. A particularly attractive possibility might involve the $\mathrm{Gly}(5) \mathrm{CO}$ group in intermolecular hydrogen bonding. In a fully folded $3_{10}$ helical structure, the regular sequence of $4 \rightarrow 1$ hydrogen bonds is interrupted by the presence of Pro(8) in 11-G, resulting in a free $\mathrm{CO}$ group at $\mathrm{Gly}(5)$. We have earlier shown that distorted $3_{10}$ helical conformations can accomodate a Pro residue in the center of the helix (Venkatachalapathi \& Balaram, 1981b; Prasad \& Balaram, 1981). The possibility of conformational flexibility in this sequence has also been discussed for the corresponding alamethicin fragments (Rao et al., 1980; Nagaraj \& Balaram, 1981a).

An examination of the sequences in Figure 1 shows that for the longer channel formers, alamethicin, suzukacillin, hypelcin, and trichotoxin A-40, the central Gln residue and the Pro residue at the $\mathrm{C}$-terminal end are separated by seven amino acids in every case. This lends some credence to the hypothesis that spatial relationships between these residues is important. In all four polypeptides, the fourth residue after Gln might provide a free $\mathrm{CO}$ group for hydrogen bonding. It is tempting to hypothesize that the Gln side-chain amide group of another molecule would serve as the hydrogen donor. Assuming completely $3_{10}$ helical conformations for these peptide chains, one can define three distinct helix faces, charcterized by specific side chains. This results from the 3 -fold symmetry of the $3_{10}$ helix, together with axial translation, which brings every fourth residue to the same side of the helix. Helix association may occur with adjacent chains running parallel or antiparallel. The central position of the Gln residue in the sequences of the longer channel formers (Figure 1) suggests that both possibilities would lead to reasonably close helix packing. The Gln and Gly (or Gln + ivur residues) residues now reside in different helix faces, preventing symmetrical dimeric association. The smallest unit where such association is stereochemically satisfactory, with an appreciable central channel, from preliminary model building, appears to be the hexamer where the Gln side chain of one helix is linked to one neighbor and the Gly $\mathrm{CO}$ is linked to the other. This arrangement is schematically represented in Figure 8. Folding of the Gln side chain to form a side chain-backbone hydrogen bond, as in 11-G, would allow closer approach of the polypeptide helices, permitting additional stabilization by weak van der Waals forces. Such an arrangement is particularly relevant since hexameric aggregates have been implicated in channel functions (Boheim \& Kolb, 1978; Edmonds, 1979). The proposed organization of these polypeptide aggregates leads to a channel interior lined with nonpolar side chains. The presence of ordered water in such channels may result in efficient proton translocation across membranes. Some evidence for this has been obtained in studies which demonstrate that alamethicin and synthetic hydrophobic fragments serve as efficient uncouplers of oxidative phosphorylation in mitochondria (Mathew et al., 1981). The peptides examined in this study are too short to form transmembrane channels (Mathew et al., 1981; Nagaraj et al., 1980), precluding a correlation between ease of aggregation and membrane activity. Further studies on larger suzukacillin fragments aimed at evaluating the role of the Gln residue in modulating membrane activity are currently being pursued in this laboratory.

\section{References}

Boheim, G., \& Kolb, H. A. (1978) J. Membr. Biol. 38, 99-150.

Boheim, G., Janko, K., Liebfritz, D., Ooka, T., Konig, W. A., \& Jung, G. (1976) Biochim. Biophys. Acta 433, 182-199. Bradley, R. J., Urry, D. W., Okamoto, K., \& Rapaka, R. (1978) Science (Washington, D.C.) 200, 435-436.

Bruckner, H., Konig, W. A., Greiner, M., \& Jung, G. (1979) Angew. Chem., Int. Ed. Engl. 18, 476-477.

Edmonds, D. T. (1979) Chem. Phys. Lett. 65, 429-433.

Fujita, T., Takaishi, Y., \& Shimomoto, T. (1979) J. Chem. Soc., Chem. Commun., 413-414.

Hall, J. E. (1978) in Membrane Transport in Biology Concepts and Models (Tosteson, D. C. Ed.) Vol. 1, pp 475-531, Springer-Verlag, Heidelberg and New York.

Hruby, V. J. (1974) Chem. Biochem. Amino Acids, Pept. Proteins 3, 1-188.

Iqbal, M., \& Balaram, P. (1981a) J. Am. Chem. Soc. 103, 5548-5552.

Iqbal, M., \& Balaram, P. (1981b) Biochemistry 20, 4866-4871. 
Iqbal, M., Nagaraj, R., \& Balaram, P. (1981) Int. J. Pept. Protein Res. (in press).

Irmscher, G., Bovermann, G., Boheim, G., \& Jung, G. (1978) Biochim. Biophys. Acta 507, 470-484.

Jung, G., Konig, W. A., Liebfritz, D., Ooka, T., Janko, J., \& Boheim, G. (1976) Biochim. Biophys. Acta 433, 164-181.

Mathew, M. K., Nagaraj, R., \& Balaram, P. (1981) Biochem. Biophys. Res. Commun. 98, 548-555.

Mueller, P., \& Rudin, D. O. (1968) Nature (London) 217, 713-719.

Nagaraj, R., \& Balaram, P. (1981a) Biochemistry 20, 2828-2835.

Nagaraj, R., \& Balaram, P. (1981b) Tetrahedron 37, 1263-1270.

Nagaraj, R., Shamala, N., \& Balaram, P. (1979) J. Am. Chem. Soc. 101, 16-20.

Nagaraj, R., Mathew, M. K., \& Balaram, P. (1980) FEBS Lett. 121, 365-368.

Pandey, R. C., Carter Cook, J., Jr., \& Rinehart, K. L., Jr. (1977a) J. Am. Chem. Soc. 99, 8469-8483.

Pandey, R. C., Carter Cook, J., Jr., \& Rinehart, K. L., Jr. (1977b) J. Am. Chem. Soc. 99, 5205-5206.

Pandey, R. C., Meng, H., Carter Cook, J., Jr., \& Rinehart, K. L., Jr. (1977c) J. Am. Chem. Soc. 99, 5203-5205.

Prasad, B. V. V., \& Balaram, P. (1981) Int. J. Biol. Macromol. (in press).

Prasad, B. V. V., Shamala, N., Nagaraj, R., Chandrasekaran, R. C., \& Balaram, P. (1979) Biopolymers 18, 1635-1646.
Rao, Ch. P., Nagaraj, R., Rao, C. N. R., \& Balaram, P. (1979) FEBS Lett. 100, 244-248.

Rao, Ch. P., Nagaraj, R., Rao, C. N. R., \& Balaram, P. (1980) Biochemistry 19, 425-431.

Smith, G. D., Pletnev, V. Z., Duax, W. L., Balasubramanian, T. M., Bosshard, H. E., Czerwinski, E. W., Kendrick, N. E., Mathews, F. S., \& Marshall, G. R. (1981) J. Am. Chem. Soc. 103, 1493-1501.

Stevens, E. S., Sugawara, N., Bonora, G. M., \& Toniolo, C. (1980) J. Am. Chem. Soc. 102, 7048-7050.

Urry, D. W. (1971) Proc. Natl. Acad. Sci. U.S.A. 68, 672-676.

Veatch, W. R., Fossel, E. T., \& Blout, E. R. (1974) Biochemistry 13, 5249-5256.

Venkatachalapathi, Y. V., \& Balaram, P. (1981a) Biopolymers 20,625-628.

Venkatachalapathi, Y. V., \& Balaram, P. (1981b) Biopolymers 20, 1137-1145.

Venkatachalapathi, Y. V., Nair, C. M. K., Vijayan, M., \& Balaram, P. (1981) Biopolymers 20, 1123-1136.

Weinstein, S., Wallace, B. A., Blout, E. R., Morrow, J. S., \& Veatch, W. (1979) Proc. Natl. Acad. Sci. U.S.A. 76, 4230-4234.

Wuthrich, K. (1976) NMR in Biological Research: Peptides and Proteins, North-Holland Publishing Co., Amsterdam.

Zanacchi, R. M., \& Moore, W. J. (1980) Aust. J. Chem. 33, $1505-1510$.

\title{
Characterization of Rat Liver Oligonucleosomes Enriched in Transcriptionally Active Genes: Evidence for Altered Base Composition and a Shortened Nucleosome Repeat ${ }^{\dagger}$
}

\author{
Ellen M. Berkowitz* and Emily A. Riggs ${ }^{\ddagger}$
}

ABSTRACT: A transcriptionally active chromatin fraction of oligonucleosome size has been separated and isolated by a modified micrococcal nuclease fractionation procedure. After mild enzymatic digestion, rat liver nuclei were lysed, and the chromatin was separated by centrifugation on linear sucrose gradients. Fractions from four regions of the gradient were pooled and labeled, from the top to the bottom, A, B, C, and $D$, respectively. Fraction A, which contained $20 \%$ or less of the total DNA, was determined to have a mean size of a hexanucleosome. By hybridization with $\left[{ }^{3} \mathrm{H}\right] \mathrm{cDNA}$ transcribed from total cytoplasmic poly(A) mRNA, DNA from

I In differentiated cells, only a small percentage of the information in chromosomal DNA is expressed (McCarthy et al., 1973). While this transcribed chromatin appears to possess a periodic nucleosome structure (Lacy \& Axel, 1975; Mathis

\footnotetext{
1 From the Department of Biochemistry, Boston University School of Medicine, Housman Research Building, Boston, Massachusetts 02118 . Received June 15, 1981. This work was supported by National Institutes of Health Grants AG00001 and AG00059.

tE.A.R. is a predoctoral fellow of the National Institutes of Health.
}

fraction A was shown to be 10-15-fold enriched in transcribing genes when compared with total DNA. This fraction also has a somewhat higher concentration of $\mathrm{AT}$ base sequences. Significant differences were observed in nucleosome phasing. Fraction $\mathbf{A}$ has the shortest repeat length, fractions $\mathrm{B}$ and $\mathrm{C}$ are intermediate, and fraction $\mathrm{D}$, which is depleted in transcribing DNA sequences, has the longest. Thus, we have isolated a chromatin fraction of oligonucleosome size enriched in transcribing genes and organized with reduced nucleosome spacing.

\& Gorovsky, 1976; Bellard et al., 1978), there is increasing evidence that transcribing genes exist in an altered conformation. First, transcribing nuclear DNA is preferentially digested by nucleases such as DNase I (Berkowitz \& Doty, 1975; Weintraub \& Groudine, 1976; Garel \& Axel, 1976) and DNase II (Gottesfeld et al., 1974). In addition, micrococcal nuclease cleaves the ovalbumin gene more rapidly than the globin gene in hen oviduct (Bellard et al., 1978), and both DNase I and micrococcal nuclease preferentially cleave ac- 